\title{
MORFOLOGI JENIS - JENIS TUMBUHAN PADA LAHAN REKLAMASI TAMBANG BATUBARA BUKIT ASAM TANJUNG ENIM
}

\author{
Dana Mega Lestari ${ }^{1 *}$, Syamsul Rizal ${ }^{2}$, Inka Dahlianah ${ }^{3}$ \\ ${ }^{1,2,3}$ Program Studi Biologi, Fakultas Sains dan Teknologi \\ Universitas PGRI Palembang \\ *e-mail:danamegalestari6@gmail.com
}

\begin{abstract}
This study on the morphology of plant species in the Bukit Asam Tanjung Enim Coal Mine Reclamation Land, has been carried out from May 2021 to June 2021. The purpose of this study was to the determine the morphology and types of plants on the coal mine reclamation land in Tanjung Enim. This study uses a deskriptive survey method. Sampling using purposive sampling with exploring techniques. The results obtained are 12 plant species, namely: Kayu putih (Melaleca leucadendra (L)), Akasia ( Acacia mangium ), Lamtoro ( Leucaena leucocephala), Mahoni ( Swietenia macrophilla King ), Tanjung ( Mimusops elengi Linn ), Waru ( Hibiscus tiliaceus ), Seru ( Schima wallichii), Kelapa sawit ( Elaeis guineensis ), Jati ( Tectona grandis ), Trembesi ( Samanea saman ), Angsana ( Pterocarpus indicus Willd), Sengon ( Paracerienthes falcataria (L)). Morphological observations on the root (Radix), stem (Caulis), leaf (Folium), flower (Flos), fruit (Fructus). System that has been obtained is a tap root (Radix primaria) and fibers root (Radix adventica). Types of woody trunk (Lignosus), single leaf types (Folium simplex) and compound (Folium compositum), single flowers and compound flowers, and there are 4 types of fruit, namely box fruit, buni fruit, stone fruit and pod.
\end{abstract}

Keywords: Morphology, Land Use

\section{ABSTRAK}

Penelitian ini tentang Morfologi Jenis - Jenis Tumbuhan Pada Lahan Reklamasi Tambang Batubara Bukit Asam Tanjung Enim, telah dilaksanakan pada bulan Mei 2021 sampai dengan bulan Juni 2021. Tujuan untuk mengetahui morfologi dan jenis - jenis tumbuhan pada lahan reklamasi tambang batubara di Tanjung Enim. Penelitian ini menggunakan metode survei deskriptif. Pengambilan sampel dengan menggunakan purposive sampling dengan menggunakan teknik menjelajah. Hasil penelitian yang didapat ada 12 spesies tumbuhan yaitu Kayu putih (Melaleca leucadendra (L)), Akasia ( Acacia mangium ), Lamtoro ( Leucaena leucocephala), Mahoni ( Swietenia macrophilla King ), Tanjung ( Mimusops elengi Linn ), Waru ( Hibiscus tiliaceus ), Seru ( Schima wallichii), Kelapa sawit ( Elaeis guineensis ), Jati ( Tectona grandis ), Trembesi ( Samanea saman ), Angsana ( Pterocarpus indicus Willd), Sengon ( Paracerienthes falcataria (L)). Pengamatan morfologi pada bagian akar (Radix), batang (Caulis), daun (Folium), bunga (Flos), buah (Fructus). Sistem perakaran yang diperoleh adalah akar tunggang (Radix primaria) dan akar serabut (Radix adventica). Jenis batang berkayu (Lignosus), jenis daun tungal (Folium simplex) dan majemuk (Folium compositum), bunga tunggal dan bunga majemuk, serta terdapat 4 jenis buah yaitu buah kotak, buah buni, buah batu dan buah polong.

Kata Kunci : Morfologi, Pemanfaatan Lahan 


\section{PENDAHULUAN}

Perusahaan yang mengelola hasil alam berupa batubara yang terletak di Tanjung Enim, Sumatera Selatan adalah PT. Bukit Asam. Penambangan dapat berdampak negatif terhadap lingkungan hidup di sekitar wilayah penambangan batubara sepeti perubahan bentang alam, penurunan estetika lingkungan, habitat hidup flora dan fauna menjadi rusak serta penurunan kualitas tanah.

Batubara berasal dari batuan hidrokarbon padat yang terbentuk dari fosil tumbuhan dalam lingkungan bebas oksigen, serta terkena pengaruh tekanan dan panas yang berlangsung lama. Proses pembentukan tersebut memerlukan waktu jutaan tahun, dari awal pembentukan yang akan menghasilkan gambut, lignit, subbituminus, bituminous, dan terakhir terbentuknya antrasit. Unsur utamanya terdiri dari karbon, hidrogen dan oksigen. Batubara adalah batuan organik yang memiliki sifat - sifat fisika dan kimia yang kompleks yang dapat ditemui dalam berbagai bentuk ( Zulkifli, 2014 ).

Kegiatan yang di pertambangan adalah untuk mengambil hasil alam berupa batubara, emas, timah dan bahan tambang lainnya. Pengambilan bahan tambang berbeda-beda mempengaruhi keadaan muka bumi, mempengaruhi kinerja fungsi hidrolisis dalam tanah, dan dapat menurunkan tingkat produktivitas tanah ( Patiung, 2011 ). Kerusakan sifat fisika dan kimia pada tanah akibat dari penggalian top soil untuk mencapai lapisan bahan tambang yang lebih dalam sehingga mengunbah topografi dan komposisi tanah permukaan ( Herjuna, 2011 ).

Dampak negatif dari kegiatan penambangan yaitu dalam waktu yang relatif singkat dapat mengubah bentuk topografi tanah dan keadaan muka tanah ( land impact ) sehingga dapat mengubah keseimbanagn sistem ekologi, dapat menimbulkan berbagai macam gangguan pencemaran akibat debu dana sap yang mengotori udara dan air serta buangan limbah tambang yang mengandung zat zat beracun, pertambangan yang dilakukan tanpa memperhatikan keselamatan kerja dan kondisi geologi lapangan dapat menimbulkan tanah longsor, ledakan tambang, keruntuhan tambang dan gempa ( Listyani, 2017 ).

Green meening (tambang ramah lingkungan) merupakan salah satu komitmen yang dibuat dan dilaksanakan oleh setiap perusahan tambang sebagai upaya mempertimbangankan kelestarian lingkungan dala aktivitas penambangan yang dilakukan. Hal tersebut untuk mewujudkan perusahaan sebagai perusahaan green meening, yaitu perusahaan yang tidak hanya merusak tetapi membantu mewujudkan kelestarian fungsi di Indonesia. Upaya tersebut dilakukan dengan cara melakuakn perbaiakan pada teknik reklamasi bekas tambang yang selesai eksploitasi ( Hirfan, 2016 ).

Revegetasi adalah suatu usahan untuk memperbaiki dan memulihkan vegetasi yang rusak supaya melalui kegiatan dan pemeliharaan pada lahan bekas tambang batubara kembali seperti penanaman awal. Tujuan revegetasi mencakup pengembalian berbagai tumbuhan yang sesuai dengan tanaman awal dan untuk menahan erosi dan seddimentasi ( Budiana, 2017 ). Tujuan dari rehabilitasi lahan bekas tambang adalah sebagai cara untuk mengembalikan tanah supaya stabil dan tidak terjadi longsoran. Selain itu tanah di perbaiki supaya nilai ekonominya bisa dikembalikan seperti rona awal lahan tersebut ( Harapan, 2016 ).

Seleksi tanaman lokal dapat dilakukan dengan mengetahui apa saja jenis pohon yang dapat di pelihara pada lahan tersebut, tanaman yang bisa tumbuh dengan cepat, penambah nitrogen, mampu 
untuk penyinaran secara penuh, beradaptasi terhadap hara rendah, mudah dilakukan penambahan, harganya terjangkau, dan bisnis bisa tersedia secara alami ( Asmarhansyah, 2017 ).

Secara bahasa morfologi berasal dari bahasa Morphologi berarti ilmu yang mempelajari bentuk luar dari tumbuhan, khusnya pada tumbuhan berbji mengenai organ-organ tumbuhnya dengan segala variasinya ( Sutarmi, 2010 ). Pada tumbuhan biasanya dimulai dari sel tumbuhan yang menyusun jaringan organ, sistem organ dan satu individu tumbuhan yang lengkap. Setiap organ penyusun tumbuhan dapat dikatakan sebagai struktur dengan fungsi yang berbeda. Biasanya dalam mempelajari hal tersebut lebih diutamakan mempelajari struktur tumbuhan dari bentuk luarnya, yang dikenal dengan istilah morfologi tumbuhan.

Pengetahuan tentang morfologi tumbuhan dapat menjadi dasar dalam mempelajari struktur penyusun tubuh tumbuhan, karena morfologi tumbuhan mencakup bagian - bagian yang merupakan struktur pokok yang dapat diamati yaitu mulai dari bagian pada akar, batang, daun, bunga, serta buahnya dan struktur lain yang terbentuk dari proses metamorfosis tumbuhan ( Rosanti, 2013 ).

Morfologi batang untuk vegetasi tingkat pohon dapat menjadi karakteristik arsitektur pohon, mulai dari pola pertumbuhan batang, cabang serta ranting yang berbeda. Hal ini kemudian dapdiartikan bahwa pohon - pohon memiliki arsitektur pohon tertentu (Hasanuddin, 2013). Batang merupakan bagian tumbuhan yang sangat penting, mengingat tempat serta kedudukan batang bagi tubuh tumbuhan, batang sering dikatakan sebagai sumbu tubuh tumbuhan. Batang sebagian besar tumbuhan terletak dipermukaan tanah namun ada pula tumbuhan yang tidak memiliki batang ( Planta acualis ) walaupun sebenarnya memiliki batang hanya saja sangat pendek sekali sehingga seakan tidak memiliki batang ( Haryani, 2012 ).

Pada bagian besar tumbuhan daun hanya terdiri dari satu atau dua bagian saja, yakni hanya helai daun saja, tangkai dan helai daun saja, helai daun dan pelepah, atau hanya memiliki tangkau daun saja. Daun daun tersebutlah yang dikatakan atau tergolong kedalam daun yang tak lengkap. Atas dasar konfigurasinya daun dapat dibedakan menjadi dua yaitu daun tunggal dan daun majemuk ( Latifa, 2015 ).

Bunga merupakan alat perkembangbiakan generatif, tempat terjadinya peristiwa penyerbukan dan pembuahan yang didalamnya terdapat biji. Selain berfungsi sebagai alat perkembangbiakan, bunga juga memiliki banyak manfaat bagi kehidupan manusia, antara lain sebagai sumber makanan, minuman, dan lain sebagainya (Purnobasuki hhh, 2014). Berdasarkan uraian diatas dilakukan penelitian tentang morfologi seperti akar, batang, daun, bunga dan buah dari berbagai jenis - jenis tumbuhan yang ada di lahan rekalamasi bekas tambang

\section{BAHAN DAN METODE}

Penelitian ini telah dilaksanakan dilahan reklamasi pascatambang batubara PT. BA, Tanjung Enim, Sumatera Selatan. Penelitian ini dilaksanakan pada bulan April - Juni 2021. Penelitian dilaksanakan pada lahan reklamasi usia 10 tahun.

Penelitian ini menggunakan metode survei deskriptif dengan pengambilan sampel menggunakan Purposive Sampling, dengan teknik menjelajah menyusuri areal reklamasi pertamabangan batubara kurang lebih berjalan hanya sekitar $5 \mathrm{~km}$. 
Penentuan lokasi penelitian terletak di Tambang Batubara Air Laya pada usia lahan 10 tahun dengan luas hutan 100 ha. Penentuan lokasi bertujuan untuk mengetahui bagaimana kondisi lahan serta berapa jenis tumbuhan yang terdapat pada lahan tersebut.

Pengambilan data tumbuhan dilakukan secara langsung dengan teknik menjelajah lahan reklamasi tambang batubara. Data yang diperoleh dari pengamatan secara langsung pada setiap tumbuhan yang ada di lahan tersebut dengan melihat morfologi pada bagian bagian tumbuhan yaitu akar, batang, daun, bunga dan buah.

\section{HASIL DAN PEMBAHASAN}

Dari hasil penelitian yang telah dilakukan pada areal reklamasi ditemukan dua belas spesies tumbuhan yaitu Kayu Putih (Melaleuca leucadendra (L.)),
Akasia (Acacia mangium), Lamtoro (Leucaena leucocephala), Mahoni (Swietenia macrophilaKing), Tanjung (Mimusops elengi Linn), Waru (Hibiscus tiliaceus), Seru/puspa (Schima wallichi), Kelapa Sawit (Elaeis guineensis), Jati (Tectona grandis), Trembesi (Samanea saman), Angsana (Pterocarpus indicus Willd), Sengon (Paracerienthes falcataria (L)). Terdapat dua Kelas yaitu Monocotyledoneae satu jenis dan sebelas jenis Dicotyledoneae. Ordo yang di dapat ada sembilan yaitu Myrtales, Fabales, Sapindales, Ebenales, Malvales, Ericales, Palmales, Lamiales, Leguminoles. Famili yang didapat berjumlah sembilan yaitu Myrtaceae, Fabaceae, Meliacecae, Sapotaceae, Malvaceae, Theaceae, Palmaceae, Lamiaceae, Mimosaceae. Genus yang didapat ada dua belas yaitu Melaleuca, Acacia, Leucaena, Swietenia, Mimusops, Hibiscus, Schima, Elaeis, Tectona, Albiziar Merr, Pterocarpus, Paraserianthes.

Tabel 1. Jenis - jenis Tumbuhan Pada Lahan Reklamasi Tambang Batubara Bukit Asam

\begin{tabular}{lll}
\hline No. & Nama Lokal & \multicolumn{1}{c}{ Nama Latin } \\
\hline 1. & Kayu Putih & Melaleuca leucadendra $($ L. $)$ \\
2. & Akasia & Acacia mangium \\
3. & Lamtoro & Swietenia macrophilla King \\
4. & Mahoni & Mimusops elengi Linn \\
5. & Tanjung & Hibiscus tiliaceus \\
6. & Waru & Schima wallichii \\
7. & Seru / Puspa & Elaeis guineensis \\
8. & Kelapa Sawit & Tectona grandis \\
9. & Jati & Samanea saman \\
10. & Trembesi & Pterocarpus indicus Willd \\
11. & Angsana & Paracerienthes falcataria $($ L. $)$ \\
12. & Sengon &
\end{tabular}


Tabel 2. Klasifikasi Jenis - jenis Tumbuhan Pada Lahan Reklamasi Tambang Batubara

\begin{tabular}{|c|c|c|c|c|c|}
\hline No. & Kelas & Ordo & Famili & Genus & Spesies \\
\hline 1. & Monocotyledonae & Palmales & Palmaceae & Elaeis & Elaeis guineensis \\
\hline 2. & Dicotyledone & Myrtales & Myrtaceae & Melaleuca & Melaleuca leucadendron (L.) \\
\hline 3. & & Fabales & Fabaceae & Acacia & Acacia mangium \\
\hline 4. & & & & Leucaena & Leucaena leucocephala \\
\hline 5. & & & & Samanea & Samanea saman \\
\hline 6. & & & & Pterocarpus & Pterocarpus indicus Willd \\
\hline 7. & & Malvales & Malvaceae & Hibiscus & Hibiscus tiliaceus \\
\hline 8. & & Ericales & Theaceae & Schima & Schima wallichii \\
\hline 9. & & Lamiales & Lamiaceae & Tectona & Tectona grandis \\
\hline 10. & & Sapindales & Meliaceae & Swietenia & Swietenia macriphyllaKing \\
\hline 11. & & Ebenales & Sapotaceae & Mimusops & Mimusops elengi Linn \\
\hline 12. & & Leguminosae & Mimosaceae & Paraserianthes & Paraserianthes falcataria (L.) \\
\hline
\end{tabular}

Morfologi tumbuhan di lokasi lahan reklamasi tambang batubara yang di amati meliputi akar (Radix), batang (Cauli), daun (Folium), bunga (Flos), dan buah (Fructus). Hasil penelitian yang di temukan terdiri dari akar tunggang (Radix primaria) dan akar serabut (Radix adventica), jenis batang yang di dapat jenis batang berkayu (Lignosus), jenis jenis daun ada daun tunggal (Folium simplex) dan ada daun majemuk (Folium compositum), ada dua jenis bunga yang di dapat yaitu bunga tunggal (Planta unifloris) dan bunga majemuk (Anthotaxis), terdapat empat jenis buah dari 7 tujuh jenis tumbuhanyang ada di lahan reklamasi bekaas tambang batubara yaitu buah polong (Legumen), buah kotak, buah buni, dan buah batu.

Tumbuhan yang memiliki sistem perakaran serabut (Radix adventica) hanya tumbuhan kelapa sawit (Elaeis guineensis), akar tunggang (Radix primaria) terdapat pada semua jenis tumbuhan kecuali pada tumbuhan sawit. Jenis batang (Caulis) semua jenis tumbuhan merupakan batang berkayu (Lignosus), jenis jenis daun (Folium) pada setiap tumbuhan berbeda ada yang termasuk kedalam daun majemuk tunggal
(Folium simplex) yaitu tumbuhan kayu putih (Melaleuca leucadendra (L)), akasia (Acacia mangium), tanjung (Mimusops elengi Linn), waru (Hibiscus tiliaceus), seru / puspa (Schima waallichii), jati (Tectona grandis), tumbuhan yang memiliki jenis daun majemuk (Folium compisitum) adalah lamtoro (Leucaenal leucacephala), mahoni (Swietenia macrophillaKing), kelapa sawit (Elaeis guineensis), trembesi (Samanea saman), angsana (Pterocarpus indicusWilld), sengon (Paracerienthes falcataria (L)).

Pada bagian bunga (Flos) terdapat dua jenis bunga yaitu bunga tunggal terdapat pada jenis tumbuhan waru (Hibiscus tiliaceus), seru/puspa (Schima wallichii), sedangkan bunga majemuk terdapat pada tumbuhan kayu putih (Melaleuca leucadendra (L)), akasia (Acacia mangium), tanjung (Mimusops elengi Linn), jati (Tectona grandis), lamtoro (Leucaenal leucacephala), mahoni (Swietenia macrophillaKing), kelapa sawit (Elaeis guineensis), trembesi (Samanea saman), angsana (Pterocarpus indicusWilld).

Jenis - jenis buah yang didapat hanya ada 4 jenis buah yang terdapat pada jenis tum buhan lamtoro (Leucaenal 
leucacephala) yaitu buah sejati jenis buah polong (Legumen), mahoni (Swietenia macrophillaKing) jenis buah kotak, tanjung (Mimusops elengi Linn) jenis buah keras, waru (Hibiscus tiliaceus) jenis buah kotak, seru/puspa (Schima wallichii) jenis buah kotak, kelapa sawit (Elaeis guineensis) jenis buah batu, angsana (Pterocarpus indicusWilld)

\section{KESIMPULAN}

Dapat disimpulkan terdapatnya 12 jenis tumbuhan pada lahan reklamasi tambang batubara yaitu : Kayu putih (Melaleuca leucadendra (L.)), Akasia (Acacia mangium), Lamtoro (Leucaena leucocephala), Mahoni (Swietenia macrophillaKing), Tanjung (Mimusops elengi Linn), Waru (Hibiscus tiliaceus), Seru/puspa (Schima wallichii), Kelapa sawit (Elaeis guineensis), Jati (Tectona grandis), Trembesi (Samanea saman), Angsana (Pterocarpus indicus Willd), Sengon (Paracerienthes falcataria (L.)).

\section{DAFTAR PUSTAKA}

Asmarhansyah. 2017. Teknologi Peningkatan Produktivitas Lahan Bekas Tambang Timah. Jurnal Sumberdaya Lahan Volume XI Nomor 2.

Budiana, I Gede Eka. 2017. Evaluasi Tingkat Keberhasilan Revegetasi Lahan Bekas Tambang Batubara Di Pt Kitadin Site Embalut Kabupaten Kutai Kartanegara Kalimantan Timur. Jurnal Agrifor. 106 (2): 196

Harahap, F.R. (2016). Restorasi Lahan Pascatambang Timah Di Pulau Bangka. Jurnal AGRIFORR Volume XVI Nomor 1.

Herjuna, S. 2011. Pemanfaatan Bahan Humat dan Abu Terbang Untuk Reklamasi
Hirfan. 2016. Strategi Reklamasi Lahan Pasca Tambang. Jurnal Ilmiah Ilmu -Ilmu J Lillo-Ramos. 2010. Monitoring study of the mine pond reclamation Of Mina Conception, Iberian Pyrite Belt ( spain ). Environ Earth Sci 59:1275-1284 Lahan Bekas Tambang. Tesis. Sekolah Pasca Sarjana IPB. Bogor.

Latifa, R. 2015. Karakter Morfologi Daun Beberapa Jenis Pohon Penghijauan Hutan Kota Di Kota Malang. Prosiding Seminar Nasional Pendidikan Biologi 2015.

Listyani, N. 2017. Dampak Pertambangan Terhadap Lingkungan Hidup Di Kalimantan Selatan Dan Implikasinya Bagi Hak - Hak Warga Negara. Jurnal Al'Adl Volume IX Nomor 1 Januari April 2017. ISSN 1979/4940/ ISSN-E 2477-0124.

Patiung, O. 2011. Pengaruh Umur Reklamasi Lahan Bekas Tambang Praktek Kerja Lapangan. Bogor: Fakultas Kehutan Institut Pertanian Bogor. Rehabilotion Of Artisanal Gold Mining Land in West Lombok, Indonesia:

Caracterization of Overburden and The Surrounding Soils. Jouranl Of Geology and Mining Reserch Vol. 4(1), Hal. 1-2, January 2012. ISSN 006-9766.

Purnobasuki, H, Dewi, S A, Wahyuni, K D. 2014. Variasi Morfologi Pada Beberapa Varietas hrysanthemum orifolium Ramat. Natural B, Vol. 2, No. 3.

Rosanti, D. 2013. Morfologi Tumbuhan. Jakarta. Erlangga

Zulkifli, A. (2014). Pengelolaan Tambang Berkelanjutan, Yogyakarta : Graha Ilmu. 